\title{
Pediatric Hypertension in Two University Hospitals in Cotonou, Benin: Presentation, Etiology, Management and Outcome
}

\author{
Francis Lalya ${ }^{*}$, Didier Adedemy², Yevedo Tohodjede', Marcelline d'Almeida1, \\ Linda Ayedadjou ${ }^{1}$, Maroufou Jules Alao ${ }^{3}$ \\ ${ }^{1}$ Pediatrics Unit, Centre National Hospitalier Universitaire Hubert K. Maga (CNHU-HKM), Cotonou, Benin \\ ${ }^{2}$ Pediatrics Unit, Centre Hospitalier Universitaire Départemental Borgou-Alibori, Parakou, Benin \\ ${ }^{3}$ Pediatrics Unit, Centre Hospitalier Universitaire de la Mère et de l'Enfant Lagune (CHU-MEL), Cotonou, Benin \\ Email: ${ }^{*}$ lalyafrancis@gmail.com
}

How to cite this paper: Lalya, F., Adedemy, D., Tohodjede, Y., d'Almeida, M., Ayedadjou, L. and Alao, M.J. (2018) Pediatric Hypertension in Two University Hospitals in Cotonou, Benin: Presentation, Etiology, Management and Outcome. Open Journal of Pediatrics, 8, 74-85.

https://doi.org/10.4236/ojped.2018.81010

Received: March 5, 2018

Accepted: March 27, 2018

Published: March 30, 2018

Copyright $\odot 2018$ by authors and Scientific Research Publishing Inc. This work is licensed under the Creative Commons Attribution International License (CC BY 4.0).

http://creativecommons.org/licenses/by/4.0/

\begin{abstract}
Background: Hypertension (HPT) is a major public health problem. Many studies have attempted to investigate HPT in school children. Few, however, have targeted hospital HPT. We conducted this study to describe the epidemiologic characteristics, etiologies, management, and outcome of hospital HPT in our setting. Methods: This was a prospective and descriptive study carried out from March 01 through June 30, 2017 in the pediatric departments of two university hospitals: Centre National Hospitalier Universitaire Hubert K. Maga and Centre Hospitalier Universitaire de la Mère et de L'Enfant Lagune of Cotonou, Benin. Every consecutive patient aged 3 to 18 years who was admitted to the two hospitals for any reason had his (her) BP measured. Every patient with HPT was reviewed for demographics, history and clinical examination, and laboratory investigations as appropriate. Management was done accordingly. Outcome was also recorded. Results: The hospital frequency of HPT was $1.98 \%$ (31 cases/1565 admissions). The male/female ratio was 1.06 (16 males, 15 females). Mean age was 8.5 years \pm 4.39 (range, 3 to 16 years). $74.19 \%$ patients had Body mass index within $-2 \mathrm{SD}$ and $+2 \mathrm{SD}$. Only one patient had BMI above $+3 \mathrm{SD}$. The main etiologies found were renal: acute tubular necrosis (45.16\%), acute glomerulonephritis (16.13\%), and acute pyelonephritis (12.90\%). Diuretics (64.5\%), were the main antihypertensive drugs used. A single drug therapy was used in 35.4\%, a two-drug therapy in $32.2 \%$ and a three-drug therapy in $9.6 \%$ of cases. Length of hospital stay was more than one week in $70.97 \%$ of cases. Hospital death rate for HPT was $19.35 \%$. The outcome was not known in one patient due to exit from hospital against medical advice. All the other patients fully recovered at one month post-discharge
\end{abstract}


follow-up. Conclusion: HPT presents as a symptomatic disease in our hospitals; it has a renal etiology in most cases and has significant death rate despite treatment. Advocacy with health authorities must be the way out of issues of HPT management in our setting.

\section{Keywords}

Hypertension, Hospital, Children, Benin

\section{Introduction}

Hypertension (HPT) is a major public health problem that contributes to early development of cardiovascular disease. According to the World Health Organization (WHO), one-third of the world's adults suffer from high blood pressure (BP). High BP is a very common problem among adults in Africa, with a reported prevalence of $38.1 \%$ among males, $35.5 \%$ among females (the world's highest prevalence of HPT), some countries reporting prevalence rates of $50 \%$ or higher. The prevalence of HPT has increased significantly over the past decades. There were approximately 80 million adults with HPT in sub-Saharan Africa in 2000 and projections based on current epidemiological data suggest that this figure will rise to 150 million by 2025 [1] [2].

Childhood HPT is also a reality and has been reported to be increasing, based on literature's data from different areas of the world, with prevalence ranging from $1.1 \%$ to $30 \%$ [3] [4] [5] [6] [7]. Children with higher BP, especially in case of essential HPT, are more likely to become hypertensive adults [8]. Sustained high $\mathrm{BP}$ exposes children to the same major risk factor as adults, namely stroke, coronary heart disease and renal disease [9].

However, data on childhood HPT (HPT) are not readily available, especially in Africa. From available information the prevalence of HPT in children continues to rise. Childhood risk factors for high adult blood pressure (BP) include obesity, metabolic syndrome, prematurity infants, and low birth-weight. The latter is inversely associated with the presence of cardiovascular disease and HPT [3] [10] [11] [12].

Many studies have attempted to investigate HPT in school children [13]-[21]. Few studies, however, have targeted hospital HPT in which it is found that HPT may be easily underestimated but can be potentially life-threatening in children; the latter can have transient hypertension, permanent hypertension or hypertensive crisis. These patients can present with no symptoms or with symptoms as banal as headache, nausea or vomiting and these should prompt primary clinicians to check BP in every patient. Major causes of hospital hypertension are renal, endocrine or metabolic disorders [22] [23]. Primary HPT cases are rare in infant and preschool-age children and there is a high incidence of obesity among children with essential HPT [24]. 
The figure of hospital HPT in Benin is unknown; this is the reason why we have initiated this study to describe the profile of HPT in hospitalized children with regard to hospital epidemiologic characteristics, etiologies, management, and outcome.

\section{Methods}

Settings, type and period of study: This study was carried out in the pediatric departments of two university hospitals: Centre National Hospitalier Universitaire Hubert K. Maga (CNHU-HKM) and Centre Hospitalier Universitaire de la Mère et de L'Enfant Lagune (CHU-MEL) of Cotonou, Benin. This was a prospective and descriptive study from March 01 through June 30, 2017. All registrars working in the two pediatric departments during the study period were updated on BP measurement, using the method described in the fourth report on the diagnosis, evaluation, and treatment of high BP in children and adolescents [25].

Sample's recruitment and BP measurement procedures: Every consecutive patient aged 3 to 18 years who were admitted to the two hospitals for any reason had his (her) BP measured. For interpretation of systolic and diastolic BP values, we first used the "Simple Table to Identify Children and Adolescents Needing Further Evaluation of BP" by Kaelber et al. [26]. When the readings figures, depending on age, were greater than or equal to the values of this table, the exploration of the patient's BP was continued by determining the percentile of the height of the child or adolescent using the Centers for Disease Control and Prevention growth charts.

When either the systolic or diastolic BP values found was greater than or equal to the 95th percentile, the child was suspected of high BP; so the BP was checked again twice, six hours apart. When a stage 2 high BP was found, this was checked again immediately for instant care.

The mean value of the three BP measurements was spotted again on the American BP tables. The diagnosis of HPT was made when the mean of the three readings of the systolic or diastolic BP was greater than or equal to the 95th percentile. The patients' selection is shown in Figure 1.

$\mathrm{BP}$ machines used were the $\mathrm{COMED}^{\circledR}$ aneroid sphygmomanometers, with four different sizes of interchangeable cuffs. SECA ${ }^{\oplus}$ weight machine and height gauge were also used for anthropometric data.

Every patient with HPT was reviewed for demographics, a careful history and clinical examination, and laboratory investigations as appropriate. Etiologies were investigated and management was done accordingly. The outcome was also recorded. Every patient had a minimal panel of laboratory tests, including urinalysis, urine culture, blood urea nitrogen, serum creatinine, electrolytes, blood glucose, ophthalmoscopy, electrocardiogram, renal Doppler's ultrasonography and Doppler's echocardiography. All the cases were evaluated by a pediatric nephrologist. 


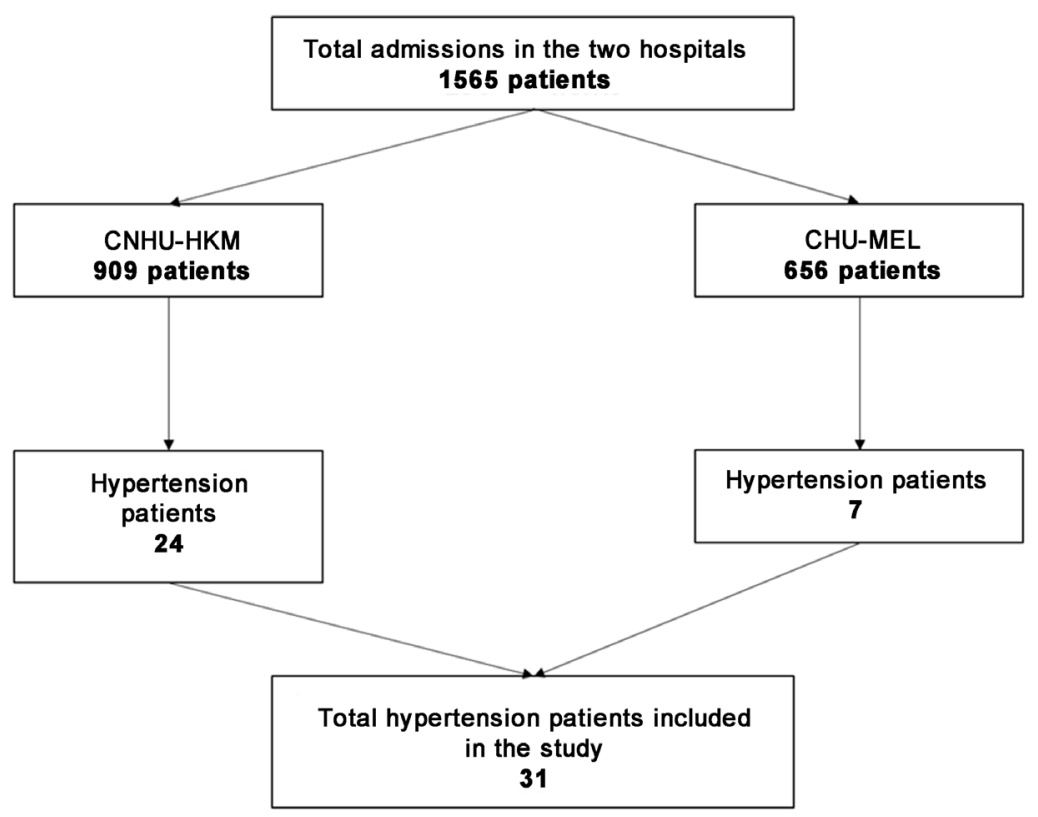

Figure 1. Patients' selection flow chart.

Data analysis: Data analysis was done using EPI info 7 software.

Ethical considerations: Families and adolescent patients received detailed information about the course of the study. Their consent was required before any inclusion. All investigation tests were charge-free for every hypertension patients included in the study.

\section{Results}

\subsection{Epidemiologic Characteristics of the Sample}

Thirty-one children with HPT were included in the study out of a total of 1565 admissions (24 cases out of 909 admissions in CNHU-HKM and 7 cases out of 656 admissions in CHU-MEL). The hospital frequency of HPT was thus $1.98 \%$ (2.64\% at CNHU-HKM and $1.07 \%$ at CHU-MEL).

The male/female ratio was 1.06 ( 16 males, 15 females). Mean age was 8.5 years \pm 4.39 (range, 3 to 16 years).

The mean weight was $23.5 \mathrm{~kg} \pm 12$ with (range, 11 to $61 \mathrm{~kg}$ ). The mean height was $132 \mathrm{~cm} \pm 25 \mathrm{~cm}(87$ to $171 \mathrm{~cm})$.

Twenty-three (74.19\%) patients had Body mass index (BMI) within -2SD and +2 SD. Seven $(22.58 \%)$ patients were below -2 SD and only one patient had BMI above +3 SD.

Most patients had poor social background since parents of twenty-seven (87\%) children did not have social welfare.

\subsection{Diagnostic Aspects of Hospital HPT}

At least one other risk factor was found in 14 (45.16\%) of the 31 hypertensive patients. Risk factors of HPT in our patients are as follows (Table 1). 
Table 1. Risk factors found in patients with HPT.

\begin{tabular}{ccc}
\hline & Risk factors & Frequency (\%) \\
\hline \multirow{3}{*}{ One risk factor } & IUGR $^{*}$ & 1 \\
& Dysuria & 5 \\
Two risk factors & Familial HPT & 6 \\
Total & Prematurity + neonatal resuscitation & 1 \\
& Nephrotic syndrome + steroid therapy & 1 \\
\hline
\end{tabular}

*IUGR: intrauterine growth retardation.

Familial HPT and dysuria were the most frequent risk factors found in the patients of this series.

HPT was discovered during the systematic measurement of BP in all admitted patients. The most frequently associated symptoms were edema, vomiting and coca cola-colored urine as shown in Table 2. Most of the time these symptoms were the motive of the consultation or reference of the patients of this series.

With respect to BP values, 18 (58\%) patients had both systolic and diastolic HPT; five (16\%) and 8 (26\%) had only systolic and diastolic HPT respectively. Eighteen (58\%) patients in this series had a stage 2 and $13(42 \%)$ a stage 1 HPT according to the National High BP Education Program Working Group on High BP in Children and Adolescents (2).

Most cases in this series had renal etiologies, with acute tubular necrosis being the leading cause of HPT followed by acute glomerulonephritis, acute pyelonephritis and nephrotic nephritic syndrome, as shown in Table 3.

No endocrine cause was found.

\subsection{Therapeutic Aspects of HPT}

Treatment was based on antihypertensive drugs, diet (low salt diet and low fluid intake). Etiologies were treated as appropriate. Bed rest was recommended for all stage 2 HPT cases. Eighty point six percent of our patients received etiologic treatment. Cases that did not receive specific etiologic treatment were: one case of glomerulonephritis, one case of acute lymphoblastic leukemia with tumor lysis syndrome, one case of brain tumor with intracranial HPT and one case of nephrotic syndrome complicated with sepsis. The latter patient died before the onset of the etiologic treatment.

Antihypertensive drugs used are indicated in Table 4.

Diuretics used in $64.5 \%$ of cases were the main antihypertensive drugs received by patients with furosemide being the leading drug used.

\subsection{Outcome of the Patients with HPT}

Six (19.35\%) patients died in hospital. The circumstances of death were acute pulmonary edema (two cases, one of which was associated with presumed uremic encephalopathy), tumor lysis syndrome with multi-organ failure, 
Table 2. Symptoms and signs associated with HPT on admission.

\begin{tabular}{ccc}
\hline & Frequency & Percentage (\%) \\
\hline Edema & 21 & 67.74 \\
Vomiting & 16 & 51.61 \\
Dark (coca cola-colored) urine & 11 & 35.48 \\
Convulsion & 7 & 22.58 \\
Abdominal pain & 3 & 9.67 \\
Dysuria & 3 & 9.67 \\
Oliguria/anuria & 5 & 16.12 \\
Coma & 2 & 6.45 \\
Diarrhea & 1 & 3.22 \\
\hline
\end{tabular}

${ }^{*}$ A child could have one or more symptoms or signs on admission.

Table 3. Etiologies of hypertension.

\begin{tabular}{ccc}
\hline & Frequency & Percentage (\%) \\
\hline Acute tubular necrosis & 14 & 45.16 \\
Acute glomerulonephritis & 5 & 16.13 \\
Acute pyelonephritis & 4 & 12.90 \\
Nephrotic nephritic syndrome & 3 & 9.67 \\
Hemolytic uremic syndrome & 2 & 6.45 \\
ALL with tumor lysis syndrome* & 1 & 3.23 \\
Epilepsy & 1 & 3.23 \\
Intracranial hypertension & 1 & 3.23 \\
Total & 31 & 100 \\
\hline
\end{tabular}

${ }^{*}$ ALL: acute lymphoblastic leukemia with tumor lysis syndrome. No endocrine cause was found.

cerebral tumor, and severe sepsis in the context of pyelonephritis. Four patients, on discharge, still had HPT (two cases of nephrotic nephritic syndrome, one case of glomerulonephritis and one case of acute tubular necrosis). The outcome was not known in one patient due to exit from hospital against medical advice.

Twenty-two (70.97\%) children had had more than one week of hospital stay. Length of hospital stay is shown in Figure 2.

All the other patients fully recovered at one month post-discharge follow-up.

\section{Discussion}

This study shows the face of HPT in two of the main hospitals in Benin. The main limitation of this study is the small sample size. A more extensive sample would certainly have enhanced the precision of this study. However, due to financial constraints regarding laboratory investigations of the cases our sample 
Table 4. Anti-hypertension medication used.

\begin{tabular}{|c|c|c|c|}
\hline & & Frequency & Percentage (\%) \\
\hline \multirow{2}{*}{ Single-drug therapy } & Furosemide & 9 & 29 \\
\hline & Captopril & 2 & 6.40 \\
\hline \multirow{3}{*}{ Two-drug therapy } & Furosemide + spironolactone & 1 & 3.20 \\
\hline & Furosemide + captopril & 7 & 22.60 \\
\hline & Captopril + amlodipine & 2 & 6.40 \\
\hline \multirow{2}{*}{ Three-drug therapy } & Furosemide + spironolactone + captopril & 1 & 3.20 \\
\hline & Furosemide + captopril + amlodipine & 2 & 6.40 \\
\hline \multirow[t]{2}{*}{ No treatment } & & 7 & 22.60 \\
\hline & Total & 31 & 100 \\
\hline
\end{tabular}

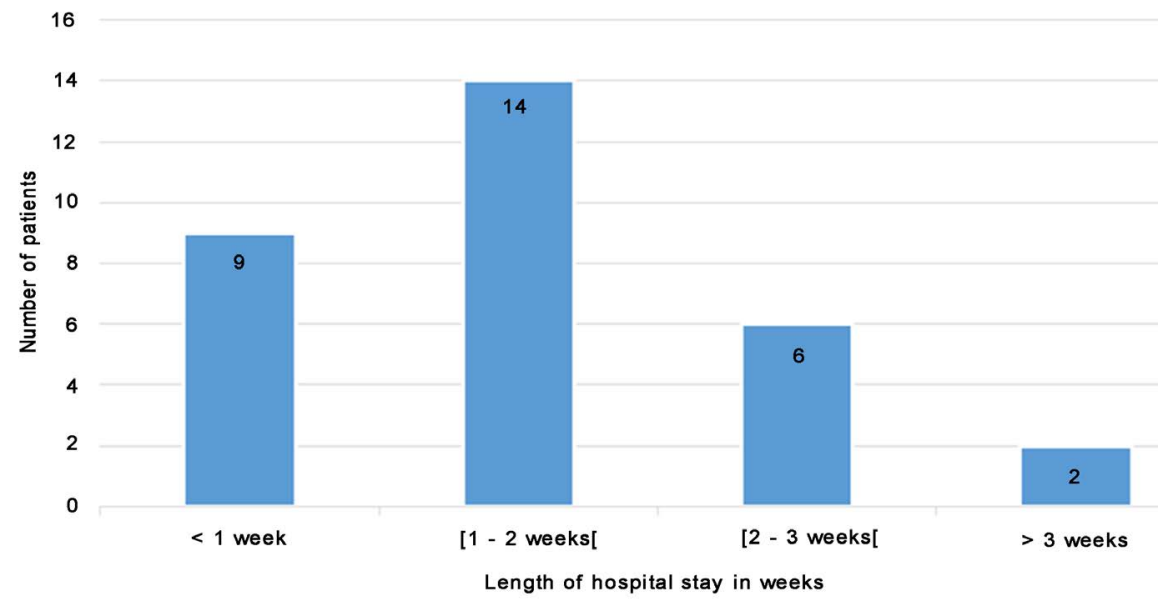

Figure 2. Length of hospital stay $(\mathrm{n}=31)$.

size was limited to 31 . Nevertheless, we do think that this consideration cannot affect the validity of our results; we chose to recruit in the hospital to try to fill the deficit of information on the profile of pediatric HPT in the hospital environment which, unlike HPT in school settings, is not much studied. Though it is known that in-hospital HPT tends to be rather secondary than primary we decided to investigate both because there is no factual data in our settings, to our knowledge, to confirm this.

Hospital frequency was $1.07 \%$ at CHU-MEL and $2.64 \%$ at CNHU-HKM. The hospital frequency at CNHU-HKM was higher than that of CHU-MEL and this higher frequency could be explained by the fact that the vast majority of the HPT in our series was of renal causes (93.55\% of the etiologies). Most health centers, 
and sometimes CHU-MEL, refer severe renal pathology cases to the CNHU-HKM pediatric ward, because of the presence of a pediatric nephrologist among the staff members. Hospital incidence of HPT in Africa is not well known. Koueta et al. in a retrospective study in Burkina Faso, found 23 cases of HPT in nine years [27].

The choice of the age range of recruitment from three years was motivate on the one hand by the fact that recommendations are to make a systematic BP check in every child who is seen in medical setting [25] and, by the non-availability of appropriate (oscillometric) device to measure BP in children below three years of age on the other hand.

Looking at comorbidities and risk factors, we evaluated body mass index by age because obesity is often correlated with high BP [28] [29] [30]. In a study in Dakar by Diouf et al. HPT was found in $25.5 \%$ of obese children [31]. But $96.77 \%$ of the children in our series were not obese. In fact, malnutrition in our setting is more prevalent than obesity according to the Benin 2011-2012 Population Health Survey where the investigators found that $45 \%$ of children under five years of age suffer from chronic malnutrition [32].

A risk factor for HPT was found in $45.16 \%$ of our patients. The most frequently encountered risk factors were a family history of HPT and a history of dysuria. There is a relationship between not only the BP of children and that of their parents but also that of their siblings [33] [34] [35] [36]. These family factors may be present in essential HPT as well as in some overt genetic diseases in which HPT is present. But we can see in Table 3, all the patients in this series have secondary HPT since an identifiable cause could be found, so the relevance of these factors is questionable.

Regarding diagnostic aspects, high BP was discovered during the systematic measurement of BP in every single patient being admitted to the hospital. This might explain the seemingly high rate of detection in our study versus that by Koueta et al. who found 21 cases in nine years in a retrospective study [27] In another retrospective study by Coulibaly et al. including 62 children with renal diseases in Ivory Coast, BP was taken in only 17 (27.9\%) of patients [37] underlining the need to systematically screen and measure BP in every child on admission in our hospitals.

All patients were symptomatic on admission and $58 \%$ had stage 2 HPT. These are in favor of secondary HPT. Indeed, the presence of symptoms and the high readings figures are indicative of secondary HPT [25] [38] and should prompt, even when no cause seems evident, to sustainably look for one.

Ninety-three point fifty-five percent of etiologies of high BP in our series were renal, with the most frequent causes being acute tubular necrosis $(45.16 \%)$, glomerulonephritis (16.13\%) and pyelonephritis (16.13\%). Renal parenchymal diseases are recognized as the leading cause of secondary HPT [39] [40]. The high frequency of acute tubular necrosis is probably related to the high prevalence of intravascular hemolysis with hemoglobinuria in our setting. In a previous study carried out at CNHU-HKM in Cotonou, we found that $96.2 \%$ of patients with 
malaria-associated acute kidney injury had intravascular hemolysis [41].

Low salt diet was a mainstay of the treatment and was prescribed to all patients because it is considered as an essential part of high BP management. It is particularly indicated when HPT is associated with fluid retention. It is associated with a reduction in blood pressure in a range from 1 to $3 \mathrm{mmHg}$ [42] [43]. For the remaining part, every effort had been made to comply with recommendations [25] though this was sometimes difficult due to resources limitation and availability of drugs. Diuretics were the most used drugs due to fluid overload in most patients. Other antihypertensive medications classes included angiotensin-converting enzyme inhibitors and calcium channel blockers; these drugs are readily available and quite affordable in our setting.

The rate of lethality in our series was $19.35 \%$. Circumstances of death were related to the background disease. Although some signs of HPT end-organ damage were present (encephalopathy, heart failure and renal failure), it is unlikely that they were due to HPT itself.

With regard to hospitalization, 22 (70.97\%) children had had more than one week of hospital stay, with most parents ( $87 \%$ of cases) not having social welfare. This lengthy hospital stay was due to the fact that, in spite of our supporting of costs related to explorations in these patients, parents had to pay for other hospitalization costs. This highlights the fact that HPT is a costly disease which has to be addressed in a resource-limited setting. Advocacy with health authorities must be the way out of issues of HPT management in our setting.

\section{Conclusion}

HPT is relatively frequent in our university hospitals and affects both boys and girls in the same proportion. It presents as a symptomatic disease, has a renal etiology in most cases and has significant death rate despite treatment. Advocacy with health authorities must be the way out of issues of HPT management in our setting.

\section{References}

[1] Collaboration NCDRF (2017) Worldwide Trends in Blood Pressure from 1975 to 2015: A Pooled Analysis of 1479 Population-Based Measurement Studies with 19.1 Million Participants. Lancet, 389, 37-55. https://doi.org/10.1016/S0140-6736(16)31919-5

[2] World Health Organization (2018) The Health of the People: What Works. http://www.who.int/bulletin/africanhealth2014/disease_threats/en/

[3] Assadi, F. (2014) Childhood Hypertension: A Problem of Epidemic Proportion. International Journal of Preventive Medicine, 5, S1-S3.

[4] Hansen, M.L., Gunn, P.W. and Kaelber, D.C. (2007) Underdiagnosis of Hypertension in Children and Adolescents. JAMA, 298, 874-879. https://doi.org/10.1001/jama.298.8.874

[5] LaRosa, C. and Meyers, K. (2010) Epidemiology of Hypertension in Children and Adolescents. Le Journal médical libanais, 58, 132-136. 
[6] Sorof, J.M., Lai, D., Turner, J., Poffenbarger, T. and Portman, R.J. (2004) Overweight, Ethnicity, and the Prevalence of Hypertension in School-Aged Children. Pediatrics, 113, 475-482. https://doi.org/10.1542/peds.113.3.475

[7] Zarbock, S. (2018) Hypertension in Children 2005. https://www.medscape.com/viewarticle/510523\#vp_1

[8] Bassareo, P.P., Bassareo, V., Iacovidou, N. and Mercuro, G. (2014) Antihypertensive Therapy in Children: Differences in Medical Approach between the United States and Europe. Current Medicinal Chemistry, 21, 3121-3131. https://doi.org/10.2174/0929867321666140304093848

[9] Berenson, G.S.S.S., Bao, W., Newman, W.P., Tracy, R.E. and Wattigney, W.A. (1998) Association between Multiple Cardiovascular Risk Factors and Atherosclerosis in Children and Young Adults. New England Journal of Medicine, 338, 1650-1656. https://doi.org/10.1056/NEJM199806043382302

[10] Assadi, F. (2012) The Growing Epidemic of Hypertension among Children and Adolescents: A Challenging Road Ahead. Pediatric Cardiology, 33, 1013-1020. https://doi.org/10.1007/s00246-012-0333-5

[11] Daniels, S.R., Loggie, J.M., Khoury, P. and Kimball, T.R. (1998) Left Ventricular Geometry and Severe Left Ventricular Hypertrophy in Children and Adolescents with Essential Hypertension. Circulation, 97, 1907-1911. https://doi.org/10.1161/01.CIR.97.19.1907

[12] Falkner, B., Kushner, H., Onesti, G. and Angelakos, E.T. (1981) Cardiovascular Characteristics in Adolescents Who Develop Essential Hypertension. Hypertension, 3, 521-527. https://doi.org/10.1161/01.HYP.3.5.521

[13] Akgun, C., Dogan, M., Akbayram, S., Tuncer, O., Peker, E., Taskin, G., et al. (2010) The Incidence of Asymptomatic Hypertension in School Children. Journal of Nippon Medical School, 77, 160-165.

[14] Borah, P.K., Devi, U., Biswas, D., Kalita, H., Sharma, M. and Mahanta, J. (2015) Distribution of Blood Pressure \& Correlates of Hypertension in School Children Aged 5 - 14 Years from North East India. Indian Journal of Medical Research, 142, 293-300. https://doi.org/10.4103/0971-5916.166591

[15] Diaz, A. and Calandra, L. (2017) High Blood Pressure in School Children and Adolescents in Argentina over the Past 25 Years: A Systematic Review of Observational Studies. Archivos Argentinos de Pediatria, 115, 5-11.

[16] Moser, D.C., Giuliano, I.C., Titski, A.C., Gaya, A.R., Coelho-e-Silva, M.J. and Leite, N. (2013) Anthropometric Measures and Blood Pressure in School Children. Jornal de Pediatria, 89, 243-249. https://doi.org/10.1016/j.jped.2012.11.006

[17] Musil, V., Majer, M. and Juresa, V. (2012) Elevated Blood Pressure in School Children and Adolescents-Prevalence and Associated Risk Factors. Collegium Antropologicum, 36, 147-155.

[18] Sayeemuddin, M., Sharma, D., Pandita, A., Sultana, T. and Shastri, S. (2015) Blood Pressure Profile in School Children (6 - 16 Years) of Southern India: A Prospective Observational Study. Frontiers in Pediatrics, 3, 24. https://doi.org/10.3389/fped.2015.00024

[19] Urrutia-Rojas, X., Egbuchunam, C.U., Bae, S., Menchaca, J., Bayona, M., Rivers, P.A., et al. (2006) High Blood Pressure in School Children: Prevalence and Risk Factors. BMC Pediatrics, 6, 32. https://doi.org/10.1186/1471-2431-6-32

[20] Rumboldt, M., Pavlicevic, I., Kuzmanic, M. and Rumboldt, Z. (2008) Prevalence of Hypertension in School Children. Journal of Hypertension, 26, 610-611. https://doi.org/10.1097/HJH.0b013e3282f4836d 
[21] Chadh, S.L., Tandon, R., Shekhawat, S. and Gopinath, N. (1999) An Epidemiological Study of Blood Pressure in School Children (5 - 14 Years) in Delhi. Indian Heart Journal, 51, 178-182.

[22] Yang, W.C. and Wu, H.P. (2010) Clinical Analysis of Hypertension in Children Admitted to the Emergency Department. Pediatrics and Neonatology, 51, 44-51. https://doi.org/10.1016/S1875-9572(10)60009-5

[23] Yang, W.C., Zhao, L.L., Chen, C.Y., Wu, Y.K., Chang, Y.J. and Wu. H.P. (2012) First-Attack Pediatric Hypertensive Crisis Presenting to the Pediatric Emergency Department. BMC Pediatrics, 12, 200. https://doi.org/10.1186/1471-2431-12-200

[24] Manopunya, S. and Khositseth, S. (2010) Hypertension in Thai children: A Report from a Hospital in Suburban Area. Journal of the Medical Association of Thailand, 93, S99-S108.

[25] National High Blood Pressure Education Program Working Group on High Blood Pressure in Children and Adolescents (2004) The fourth Report on the Diagnosis, Evaluation, and Treatment of High Blood Pressure in Children and Adolescents. Pediatrics, 114, 555-576.

[26] Kaelber, D.C. and Pickett, F. (2009) Simple Table to Identify Children and Adolescents Needing Further Evaluation of Blood Pressure. Pediatrics, 123, e972-e974. https://doi.org/10.1542/peds.2008-2680

[27] Koueta, F.O., Some, A.M., Boly, C., Dao, L., Sawadogo, H., Ka-Boret, S., Nacro, B., Kam, L. and Ye, D. (2013) Profile of Arterial Hypertension in Pediatric Hospital Setting in Ouagadougou (Burkina Faso). Rev Cames Sante, 1, 42-46.

[28] Din-Dzietham, R., Liu, Y., Bielo, M.V. and Shamsa, F. (2007) High Blood Pressure Trends in Children and Adolescents in National Surveys, 1963 to 2002. Circulation, 116, 1488-1496. https://doi.org/10.1161/CIRCULATIONAHA.106.683243

[29] Parker, E.D., Sinaiko, A.R., Kharbanda, E.O., Margolis, K.L., Daley, M.F., Trower, N.K., et al. (2016) Change in Weight Status and Development of Hypertension. Pediatrics, 137, e20151662. https://doi.org/10.1542/peds.2015-1662

[30] Wirix, A.J., Nauta, J., Groothoff, J.W., Rabelink. T.J., HiraSing, R.A., Chinapaw, M.J., et al. (2016) Is the Prevalence of Hypertension in Overweight Children Overestimated? Archives of Disease in Childhood, 101, 998-1003.

https://doi.org/10.1136/archdischild-2015-309969

[31] Diouf SO, A., Sylla, A., Moreira, C., Camara, B., Signate, H.S., Ndiaye, O. and Nicolas, K. (2005) Childhood Obesity in Medical Setting in Dakar: Epidemiological Aspects and Management Issues. Médecine d'Afrique Noire, 52, 288-294.

[32] Benin Demographic and Health Survey 2011-2012. National Institute for Statistics and Economic Analysis (INSAE).

http://microdata.worldbank.org/index.php/catalog/1953

[33] Andre, J.L., Deschamps, J.P. and Gueguen, R. (1986) Familial Resemblance of Blood Pressure and Body Weight. Clinical and Experimental Hypertension. Part A: Theory and Practice, 8, 661-667. https://doi.org/10.3109/10641968609046582

[34] Jung, F.F. and Ingelfinger, J.R. (1993) Hypertension in Childhood and Adolescence. Pediatrics in Review, 14, 169-179. https://doi.org/10.1542/pir.14-5-169

[35] Niiranen, T.J., McCabe, E.L., Larson, M.G., Henglin, M., Lakdawala, N.K., Vasan, R.S., et al. (2017) Heritability and Risks Associated with Early Onset Hypertension: Multigenerational, Prospective Analysis in the Framingham Heart Study. BMJ, 357, j1949. https://doi.org/10.1136/bmj.j1949

[36] Mongeau, J.G., Biron, P. and Sing, C.F. (1986) The Influence of Genetics and Household Environment upon the Variability of Normal Blood Pressure: The Mon- 
treal Adoption Survey. Clinical and Experimental Hypertension. Part A: Theory and Practice, 8, 653-660. https://doi.org/10.3109/10641968609046581

[37] Coulibaly, P.N.A., Cissé, L., Diarrasouba, G., Egesi, M., Tia, W.M., Ouatara, G.J. and Oulai, S. (2015) Renal and Urinary Diseases of Children Admitted to the Service of Pediatrics of Treichville UTH (Abidjan). Médecine d Afrique Noire, 62, 321-326.

[38] Flynn, J.T., Kaelber, D.C., Baker-Smith, C.M., Blowey, D., Carroll, A.E., Daniels, S.R., et al. (2017) Clinical Practice Guideline for Screening and Management of High Blood Pressure in Children and Adolescents. Pediatrics, 140, e20171904. https://doi.org/10.1542/peds.2017-1904

[39] Wyszynska, T., Cichocka, E., Wieteska-Klimczak, A., Jobs, K. and Januszewicz, P. (1992) A Single Pediatric Center Experience with 1025 Children with Hypertension. Acta Paediatrica, 81, 244-246. https://doi.org/10.1111/j.1651-2227.1992.tb12213.x

[40] Arar, M.Y., Hogg, R.J., Arant Jr., B.S. and Seikaly, M.G. (1994) Etiology of Sustained Hypertension in Children in the Southwestern United States. Pediatric Nephrology, 8, 186-189. https://doi.org/10.1007/BF00865475

[41] Lalya FS, G., Bagnan, L., Alihonou, F., Tohodjede, Y., d'Almeida, M., Koumakpaï, S. and Ayivi, B. (2014) Malaria-Associated Acute Renal Failure in Children at the University Hospital CNHU-Hubert K. Maga of Cotonou, Benin. Rev Afr Anesth Med Urg, 19, 39-42.

[42] Dumler, F. (2009) Dietary Sodium Intake and Arterial Blood Pressure. Journal of Renal Nutrition, 19, 57-60. https://doi.org/10.1053/j.jrn.2008.10.006

[43] Watt, G.C., Foy, C.J., Hart, J.T., Bingham, G., Edwards, C., Hart, M., et al. (1985) Dietary Sodium and Arterial Blood Pressure: Evidence against Genetic Susceptibility. British Medical Journal (Clinical Research Ed.), 291, 1525-1528. https://doi.org/10.1136/bmj.291.6508.1525 